\title{
A LIGHTWEIGHT DYNAMIC CONE PENETROMETER FOR EVALUATION OF SHEAR STRENGTH OF NATURAL MASADO SLOPES
}

\author{
ATHAPATHTHU A. M. R.G. ${ }^{1}$, Takashi TSUCHIDA², Kazuaki SUGA², \\ and Seiji KANO ${ }^{4}$ \\ ${ }^{1}$ Member of JSCE, Dept. of Civil Eng., Hiroshima University \\ (1-4-1, Kagamiyama, Higashi-Hiroshima,739-8527, Japan) \\ E-mail:rasika@hiroshima-u.ac.jp \\ ${ }^{2}$ Member of JSCE, Professor, Dept. of Civil Eng., Hiroshima University \\ (1-4-1, Kagamiyama, Higashi-Hiroshima,739-8527, Japan) \\ E-mail:ttuchida@hiroshima-u.ac.jp \\ ${ }^{3}$ Member of JSCE, Dept. of Civil Eng, Hiroshima University \\ (1-4-1, Kagamiyama, Higashi-Hiroshima,739-8527, Japan) \\ E-mail:m054246@hiroshima-u.ac.jp \\ ${ }^{4}$ Member of JSCE, Assistant Professor, Dept. of Civil Eng, Hiroshima University \\ (1-4-1, Kagamiyama, Higashi-Hiroshima,739-8527, Japan) \\ E-mail:skano@hiroshima-u.ac.jp
}

\begin{abstract}
This paper presents a simple methodology for determination of in situ shear strength parameters by recently developed lightweight dynamic cone penetrometer. A series of laboratory calibration lightweight dynamic cone penetration tests, and direct shear tests with pore water pressure measurements were conducted at different void ratios and degrees of saturation. Based on the laboratory calibration test results, a method of determining void ratio, $e$ from the data of cone resistance, $q_{d}$ was established for different degrees of saturation. A method of determining shear strength parameters from the data of $q_{d}$ was proposed based on the correlations developed between void ratios with $q_{d}$ and shear parameters.
\end{abstract}

Key Words : Masado, cone penetration test, direct shear test, degree of saturation, void ratio

\section{INTRODUCTION}

Masado, residual sandy soils of heavily weathered granite, is widely spread over Hiroshima prefecture, the southwestern part of Japan. The landscape of the area is mainly consisted of mountainous terrains, which rises from $200 \mathrm{~m}$ to $500 \mathrm{~m}$ from the mean sea level, underlain by severely fractured granite1). Due to adverse topographical and geological conditions, it has been reported in many instances that heavy rainfall had repeatedly caused shallow slope failures often with disastrous consequences damaging life, property, and infrastructure in the region ${ }^{1,2), 3)}$. Failure of these unstable slopes not only puts the lives and properties at risk, but also has adverse effects on day-to-day activities in the region. At present, 32,000 natural slopes, 22,000 planer slopes and 10,000 valley slopes, are found to be susceptible to landslide disasters in Hiroshima Prefecture, the highest number of any prefecture in Japan ${ }^{3), 4)}$. In order to mitigate anticipated slope failures in the region, Hiroshima prefectural government has been already developed a risk assessment system based on rainfall data and past records of failures. However, well documented past literatures reveal that the occurrence of slope failures during heavy rainfall is due to weakening of shear strength of soils ${ }^{5), 6)}$. Also, slope failures do not occur in direct proportion to precipitation quantity, and in some years a given quantity produces many landslides while in other years the same quantity produces a few failures ${ }^{7}$. Due to these facts, the use of existing risk assessment system for accurate prediction of failures in the region is in doubt. Moreover, the present system was found to be developed without carrying out any reliable slope stability analyses. Therefore, it is extremely important to enhance the present risk assessment system in terms of proper geotechnical inputs for better understanding of slopes vulnerability to failure in the region. 
Although some research has been conducted on Masado soils by past researchers ${ }^{1,3), 8)}$, the shear strength characteristics are not well documented in the literature. It appears that no attempt has been made to study the effect of matrix suction on the shear strength of Masado soils at various stages of degrees of saturation and void ratios. The geotechnical findings of similar sandy soils cannot be readily applicable due to own specific characteristics of Masado soils. It has been reported that many difficulties were encountered in determining their shear strength at the laboratory due to difficulties in extruding undisturbed samples at the site ${ }^{8}$. One option to overcome such difficulties is to carry out field tests to determine the shear parameters. Recently, the use of in-situ tests together with laboratory tests have become an expedient and cost effective way to determine shear strength parameters of soils.

Presently available conventional field tests (SPT, CPT etc.) for determination of shear strength are not available for natural slopes with gradients more than $25^{\circ}$. The portable dynamic cone penetration test (PDCPT), in which a $25 \mathrm{~mm}$ diameter cone is penetrated by a blow of free fall of $5 \mathrm{Kg}$ weight and the blow count $N_{d}$ for $10 \mathrm{~cm}$ penetration is measured, has been widely used in Japan as practical substitution for SPT test ${ }^{9)}$. However, the method to determine the strength parameters of Masado soils using $N_{d}$ values are not established and for the most 32,000 natural slopes vulnerable to heavy rain, the reliable slope stability analyses have not been carried out. Therefore, there is a need for an efficient field device which can be handled easily, cost effective, and portable to determine the strength parameters reliably for stability analyses. Recently, a lightweight dynamic cone penetrometer (LWDCPT) was developed for the purpose of quality control of embankments and proved its reliability in some Europe countries as a field investigation tool. This research was proposed to investigate the applicability of LWDCPT in determining the in-situ strength of natural Masado slopes found in the region. This paper discusses a methodology of determining shear parameters from the data of LWDCPT at various stages of void ratios and degrees of saturation.

\section{GEOTECHNICAL PROPERTIES OF MASADO SOILS}

\section{(1) Mechanical properties of Masado Soils}

Masado is a sandy residual soil of decomposed granitic rocks of igneous origin. Due to differential weathering process over the years, Masado exhibits variable composition of secondary minerals and unchanged primary minerals such as quartz result in variable material properties even within the same weathering grade. The grading curves of Masado soils, collected from different grid locations described later in this paper, are shown in Fig.1. Masado mainly consists of sand with considerable amount of gravel particles interconnected with small fraction of fine particles. Table 1 summarizes some of the physical properties of Masado soils. It can be observed that the properties are varying in wide range of values.

\section{(2) Shear strength equation for unsaturated soils}

Shear strength of saturated soils had been addressed in terms of effective stress concepts by many researchers and are readily available in the literature. During the past few decades, attempts have been made to understand the shear strength of unsaturated soils.

In mathematical form, Terzaghi's effective stress $\sigma^{\prime}$ is expressed as follows ${ }^{10)}$.

$$
\sigma^{\prime}=\sigma-u_{w}
$$

where:

$\begin{array}{ll}\sigma & =\text { total stress, and } \\ u_{w} & =\text { pore water pressure. }\end{array}$

Bishop ${ }^{11)}$ proposed a modified form of Terzaghi's principle of effective stress as shown in Eq.(2).

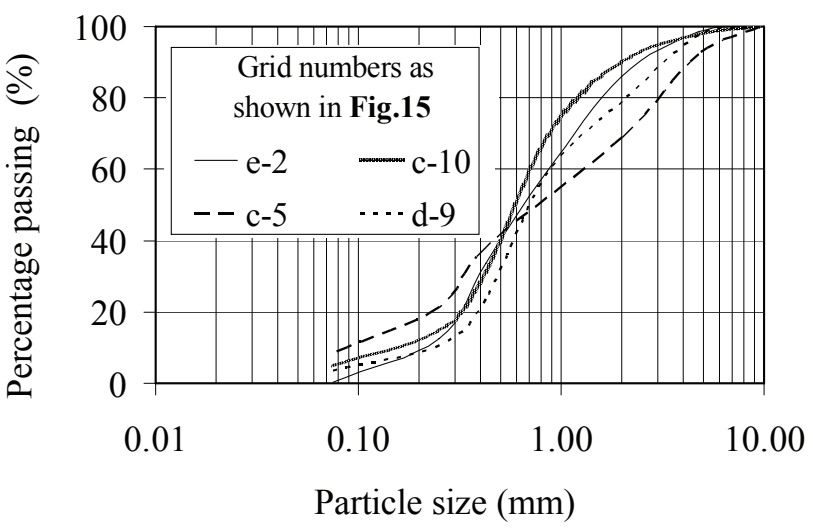

Fig.1 Grading curves of natural Masado soils

Table 1 Some properties of Masado soils ${ }^{3)}$

\begin{tabular}{|l|l|}
\hline Property & Range of values \\
\hline Wet density $\mathrm{g} / \mathrm{cm}^{3}$ & $1.38-1.79$ \\
\hline Dry density $\mathrm{g} / \mathrm{cm}^{3}$ & $1.19-1.52$ \\
\hline Soil particle density $\mathrm{g} / \mathrm{cm}^{3}$ & $2.56-2.62$ \\
\hline Void ratio & $0.71-1.14$ \\
\hline Saturated permeability $\mathrm{cm} / \mathrm{s}^{*} 10^{-3}$ & $1.33-4.72$ \\
\hline
\end{tabular}




$$
\sigma^{\prime}=\left(\sigma-u_{a}\right)+\chi\left(u_{a}-u_{w}\right)
$$

where:

$$
u_{a} \quad=\text { pore air pressure, }
$$

$\left(\sigma-u_{a}\right)=$ net normal stress,

$\left(u_{a}-u_{w}\right)=$ matric suction, and

$\chi \quad=$ a parameter depending on the degree of saturation of the soil. The magnitude of the $\chi$ is unity for a saturated soil and zero for a totally dry soil12).

Shear strength at failure $\tau_{f}$ can be expressed by incorporating the modified effective stress as shown in Eq.(2) into the classical Mohr-Coulomb failure criterion as follows.

$$
\tau_{f}=c^{\prime}+\left[\left(\sigma-u_{a}\right)+\chi\left(u_{a}-u_{w}\right)\right] \tan \phi^{\prime}
$$

where:

$\begin{array}{ll}\tau_{f}, & =\text { shear strength at failure, } \\ c^{\prime} & =\text { effective cohesion and }, \\ \phi^{\prime} & =\text { effective angle of internal frictional. }\end{array}$

The relationship between $\chi$ and the degree of saturation was established experimentally by several researchers for silt ${ }^{13}$ and boulder clay and clay shale ${ }^{14)}$ and are available in the literature. However, the limitations of quantifying parameter $\chi$ had been reported both theoretically and experimentally ${ }^{15}$.

Fredlund et al. have proposed a relationship to explain the shear strength of unsaturated soils in terms of two independent stress state variables as shown in Eq.(4) ${ }^{16), 17), 18)}$.

$$
\tau_{f}=c^{\prime}+\left(\sigma-u_{a}\right) \tan \phi^{\prime}+\left(u_{a}-u_{w}\right) \tan \phi^{b}
$$

Where $\phi^{\prime}$ and $\phi^{b}$ are angle of internal friction associated with the net normal stress state variable and angle indicating the rate of increase in the shear strength relative to matric suction respectively. This equation has been widely used to analyze the shear strength parameters since its development due to the simplicity in handling of two stress state variables. By equating Eq.(3) and Eq.(4) the parameter $\chi$, proposed by Bishop, can be expressed as follows.

$$
\chi=\frac{\tan \phi^{b}}{\tan \phi^{\prime}}
$$

It appears that $\phi^{\prime}>\phi^{b}$ in all state of unsaturations $(0<\chi<1)$ and at fully saturation condition $(\chi=1)$ both angles are identical.

Different form of shear strength equation for unsaturated soils in terms of volumetric water content is available in the literature as shown in Eq.(6) ${ }^{12), 19)}$.

$$
\tau_{f}=c^{\prime}+\left(\sigma_{n}-u_{a}\right) \tan \phi^{\prime}+\left(u_{a}-u_{w}\right)\left[\left(\frac{\theta_{w}-\theta_{r}}{\theta_{s}-\theta_{r}}\right) \tan \phi^{\prime}\right]
$$

where:

$\theta_{w}=$ volumetric water content,

$\theta_{s}=$ saturated volumetric water content, and

$\theta_{r} \quad=$ residual volumetric water content.

The Parameter $\chi$ can be expressed in terms of volumetric water content by equating Eq.(3) and Eq.(6) as bellow.

$$
\chi=\frac{\theta_{w}-\theta_{r}}{\theta_{s}-\theta_{r}}
$$

For determination of the parameter, $\chi$, from Eq.(7), the residual volumetric water content, $\theta_{r}$, has to be estimated from the soil-water characteristic curve. From the basic soil parameters, the volumetric water content can be expressed as follows.

$$
\theta=\frac{S e}{1+e}
$$

By substitution of Eq.(8) into Eq.(7), the parameter, $\chi$ can be expressed in terms of void ratio and degree of saturation. For very small values of residual volumetric water content and a particular value of a void ratio, the parameter, $\chi$ is approximately similar to the degree of saturation. Therefore, the parameter, $\chi$ can be replaced by degree of saturation ' $S$ ' in Eq.(3) as shown in Eq.(9).

$$
\tau_{f}=c^{\prime}+\left(\sigma_{n}-u_{a}\right) \tan \phi^{\prime}+\left(u_{a}-u_{w}\right)\left\lfloor S \tan \phi^{\prime}\right\rfloor
$$

The Eq.(9) is similar to that proposed by Oberg and Sallfors ${ }^{20)}$. They stated that the proposed hypothesis can be successfully applied for non-clayey soils and for degrees of saturation larger than $50 \%$ where the parameter, $\chi$ proposed by Bishop, could be roughly replaced by the degree of saturation. Further, it has been shown that the shear strength parameters calculated for silts and sands from Eq.(9) were in good agreement with those found in the literature.

\section{(3) Laboratory direct shear box tests}

The laboratory testing program involved the use of conventional direct shear apparatus modified for measurement of pore water pressure. The modified direct shear test apparatus is shown in Fig.2. A ce- 
ramic disk of $200 \mathrm{kPa}$ air entry value was sealed onto the bottom half of the shear box to facilitate the measuring of pore water pressure. The lower part of shear box is connected to a motor, through a gear box for the application of horizontal force to the specimen while the upper part of the shear box is connected to the loading ram. Dial gauges connected to data logger through transducers were used for measurements of horizontal and vertical displacements.

\section{(4) Sample preparation and testing program}

Soil samples collected at Gagara Mountain in Hiroshima prefecture were fairly air dried and pass through $2 \mathrm{~mm}$ sieve. Reconstituted specimens were prepared in carrying out laboratory direct shear box tests. Even though, undisturbed specimens provide better representative of natural conditions than reconstituted specimens, it is practically difficult to make undisturbed specimens to a certain degree of saturation and void ratio. Therefore, reconstituted specimens were preferred for the laboratory tests to determine shear strength parameters under different void ratios and degrees of saturation.

The testing program consisted of (i) consolidated drained direct shear box tests conducted at void ratios ranging from 0.7 to 1.0 in 0.1 increments at a constant degree of saturation (ii) Repeat of (i) at different degrees of saturation varying from $40 \%$ to $80 \%$. Direct shear tests with the measurement of pore water pressure were conducted at all cases mentioned above except for the cases at the void ratio of 1.0 .

Initial water content of the air-dried Masado soils was determined and the additional amount of water, required to make $200 \mathrm{~g}$ of soil sample to a certain degree of saturation and void ratio, was calculated. Calculated amount of water and soil were thoroughly mixed to make a uniform soil sample. Amount of soil sample required to make the direct

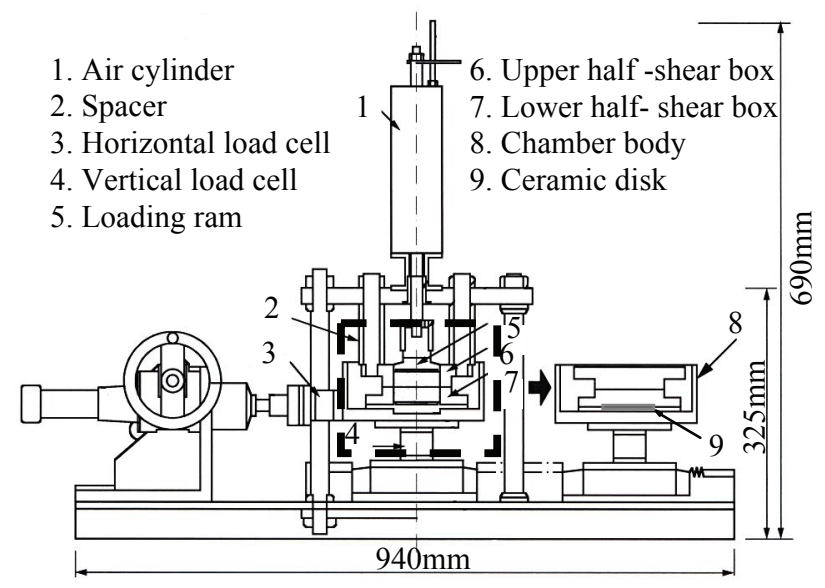

Fig.2 Modified direct shear apparatus shear box specimen was determined. Even though samples were prepared to a certain degree of saturation and void ratio, three samples were taken from the rest of soil sample to measure the water content for calculation of degree of saturation and void ratio before the test.

\section{Specimen preparation and testing procedure}

Prior to test, the measured amount of soil was filled in three layers and tamped manually by lightweight pestle $(0.24 \mathrm{Kg})$ with small compaction energy to ensure avoiding crushing of individual particles and to achieve normally consolidated state in the specimen. The tamping energy varies from $37.7 \mathrm{~kJ} / \mathrm{m}^{3}$ (for $e=0.7, \mathrm{Sr}=40 \%$ ) to $0.0 \mathrm{~kJ} / \mathrm{m}^{3}$ (for $e=1.0, S r=80 \%)$ depending on the test condition. The applied energy for tamping the samples is less than $6.4 \%\left(37.7 \mathrm{~kJ} / \mathrm{m}^{3}\right)$ of the energy required for standard proctor compaction test. Therefore, it is assumed that the energy, used for preparation of laboratory specimens, is not affected the outcomes of the results.

All tests were conducted at atmospheric air pressure $\left(u_{a}=0\right)$ under $9.8,19.6,39.2,78.4 \mathrm{kPa}$ normal stresses. The space, as described by Japanese standards ${ }^{21)}$, between upper and lower part of shear box, was maintained by three spacers, and three screws connected to upper shear box. Vertical force was applied automatically through the air cylinder connected to the pressure gauge and the data logger. Shearing was achieved by horizontally displacing the bottom half of the direct shear box relative to the top half at a constant rate of shear displacement 0.2 $\mathrm{mm} / \mathrm{min}$ as described in Japanese geotechnical standards $^{21)}$. Pore pressure was measured through the high air entry disk mounted below the sample by transducer connected to the data logger at sample preparation, consolidation, and shearing stages. The shearing process was conducted until horizontal displacement is about $7 \mathrm{~mm}$ and the real time data was recorded automatically in the data logger.

\section{(5) Total stress analysis}

Data collected from consolidated drained tests was graphically analyzed in order to find the peak shear stress at normal stress. All plots of peak shear stress verses normal stress at different degrees of saturation are shown in Fig.3 with the void ratios ranging from 0.7 to 1.0 . It can be clearly observed that shear stress decreases when degree of saturation increases. Higher void ratios implicate lower shear stresses. All failure envelops drawn for a particular void ratio showed approximately similar gradient as drawn in discontinuous lines illustrated in Fig.3. The variation of angle of internal friction, $\phi_{d}$, with void ratios is shown in Fig.4. Slight variations of $\phi_{d}$ can be observed even though $\phi_{d}$ is in- 
Failure envelope ( $\mathrm{e}=0.70$ )

Failure envelope $\mathrm{e}=(0.80)$
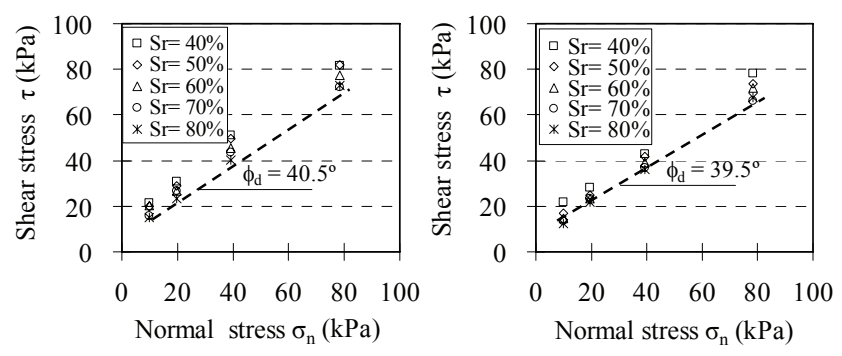

Failure Envelope $(\mathrm{e}=0.90)$

Failure envelope $(\mathrm{e}=1.0)$
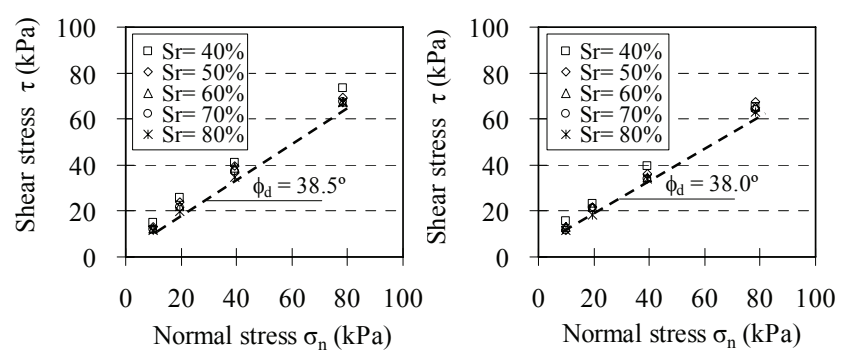

Fig.3 Failure envelopes for unsaturated Masado soils

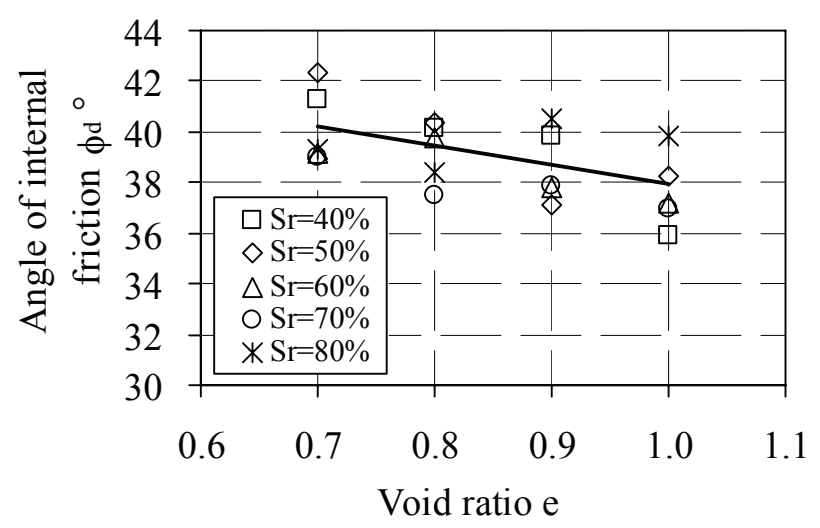

Fig.4 Variation of angle of internal friction with void ratios

dependent of degree of saturation. This may be due to assumptions made in analysis and there is a possibility of practical errors. Further analyses of the data revealed that apparent cohesion ' $c_{d}$ ' can be developed as linear functions of void ratios at different degrees of saturation. The graphical presentation of the relationship is shown in Fig.5. It appears that the apparent cohesion decreases as the degree of saturation increases. It can be observed that the apparent cohesion reduces more than 50\% when the degree of saturation varies from $40 \%$ to $80 \%$ in all range of void ratios. This gives some impression of reduction of apparent cohesion especially during the period of rainfalls when the underneath soils becoming to saturate due to penetration of water.

\section{(6) Effective stress analysis}

The purpose of this part of study was to examine

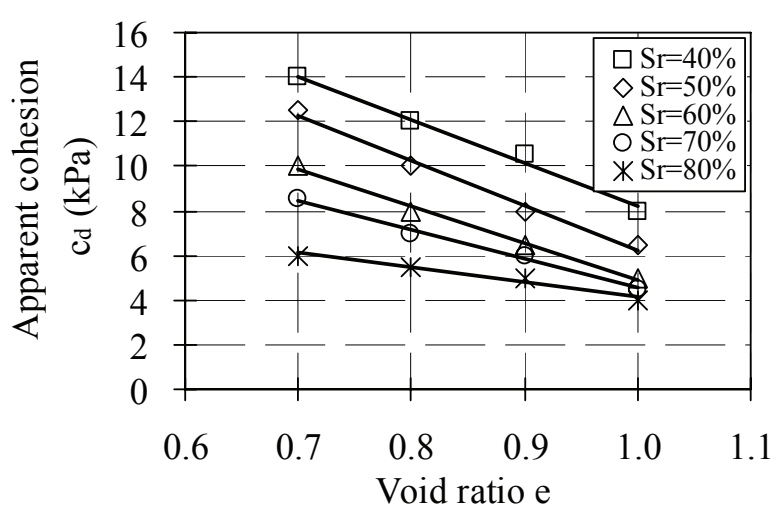

Fig.5 Variation of apparent cohesion with void ratios at different degrees of saturation

the effect of suction in determining the cohesion of Masado soils. Several researchers ${ }^{22), 23)}$ studied the shear characteristics of Masado soils. However, detailed analyses were not available in quantifying the contribution of negative pore water pressure in determining the cohesion of Masado soils at different void ratios and degrees of saturation. This research aimed to understanding the shear strength characteristics of Masado soils at different void ratios and degrees of saturation. Following subsections discuss the results obtained under the analyses.

\section{a) Variation of pore water pressure}

Pore water pressure measurements were recorded during the preparation of specimens at each case in order to make sure the specimens were in similar conditions prior to consolidation. Fig.6 shows the pore water pressure recorded during the preparation of specimens at four test cases. It can be observed that the variation of pore water pressure with the time is quite similar in each normal stress condition of a particular test case. This implies that the four reconstituted specimens, in a particular test case, are in similar condition prior to consolidation. High negative pore water pressure measurements were observed at low void ratios and low degrees of saturation during the preparation of specimens. Fig.7 illustrates the variation of pore water pressure during the shearing process under different normal stresses recorded at two test cases. It was observed that positive pore water pressures were dominant in higher degrees of saturation and higher void ratios while negative pore pressures in low degrees of saturation and low void ratios.

\section{b) Comparison of laboratory and field condi- tions: soil water characteristic curve}

Since all the laboratory tests were conducted at $u_{a}=0$, the measured pore water pressure is similar to the suction. Data collected from laboratory pore water pressure measurements under different de- 

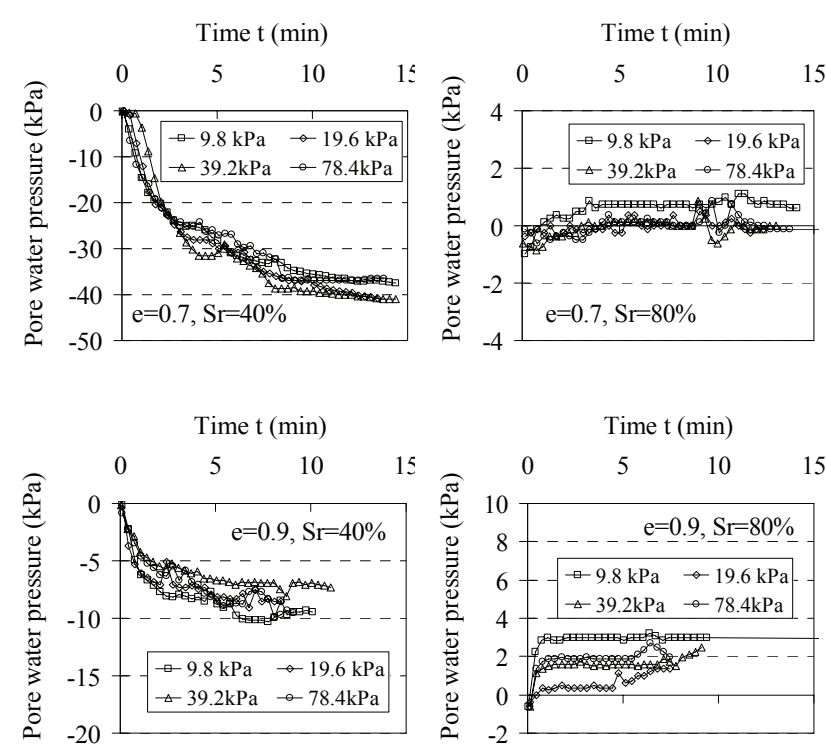

Fig.6 Pore water pressure variation during the preparation of specimens
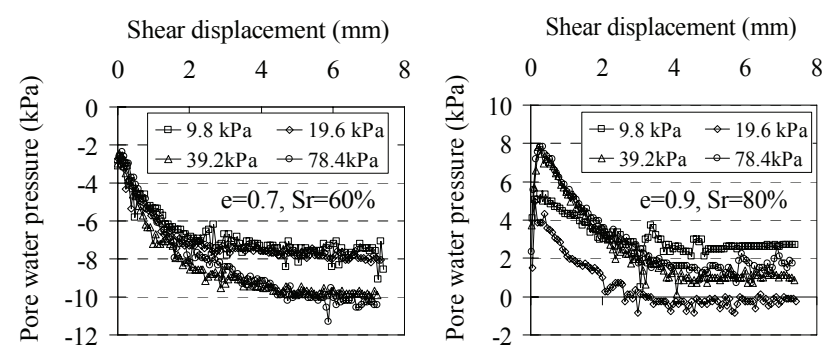

Fig.7 Pore water pressure variation during the shearing of specimens

grees of saturation and void ratios were plotted with the degree of saturation. Fig.8 illustrates the data and the proposed water retention curves based on the laboratory data. In order to compare the laboratory and field conditions, site data ${ }^{3)}$, collected by tensiometers instrumented at $50 \mathrm{~cm}$ depth under wetting and drying processes, was plotted into the Fig.8. It can be observed that the site data was followed well by the laboratory data. Therefore, fore the adopted method for preparation of specimens with different degrees of saturation is fairly similar to the natural conditions at the site. However, the site data is not available for the degree of saturation less than $60 \%$ and the tendency of variation of in-situ water retention curve is yet to be clarified. It is assumed that the site data is fairly similar to laboratory data for the degree of saturation less than $60 \%$ in analyzing the data.

\section{c) Interpretation of effective stress parameters}

The data, collected under the measurements of pore water pressure, was analyzed according to the hypothesis described by Oberg \& Sallfors ${ }^{20)}$. The effect of degree of saturation in evaluation of shear strength was calculated from Eq.(9). Fig.9 illus-

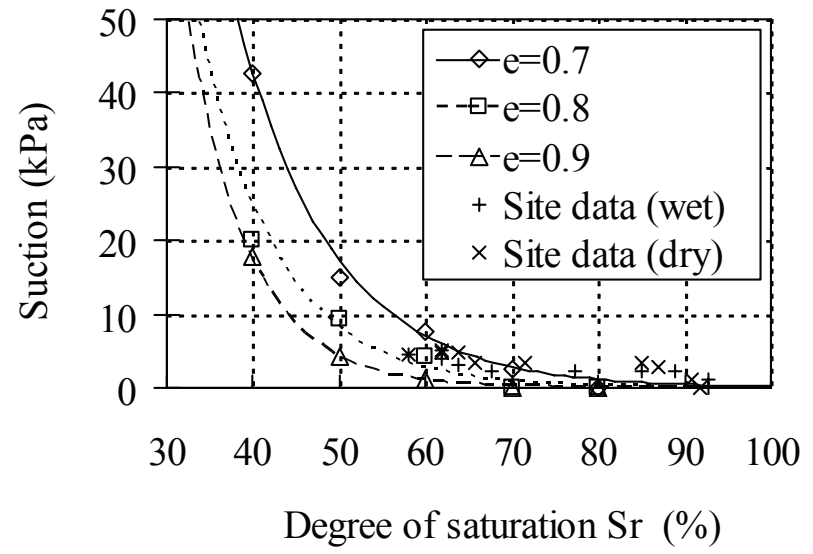

Fig.8 Relationship between degree of saturation and suction
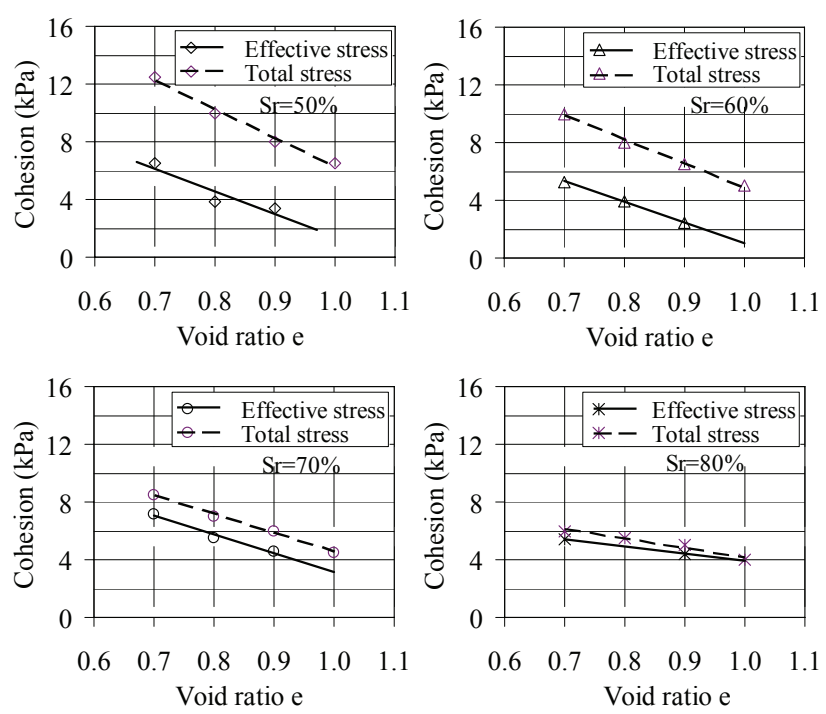

Fig.9 Variation of cohesion with void ratios for total stress state and effective stress state

trates the cohesion determined in effective stress state under different void ratios and degrees of saturation. For the easiness of understanding attenuation of cohesion due to the effect of pore water pressure at effective stress state, apparent cohesion recorded under total stress state were also presented in the Fig.9.

The reduction of apparent cohesion with the increase of void ratio under different degrees of saturation is shown in Fig.9. The reduction in cohesion due to the effect of suction is about $60 \%, 50 \%, 20 \%$, and $10 \%$ as the degrees of saturation varies form $50 \%$ to $80 \%$ in $10 \%$ increments respectively. Close review of Fig.9 indicates that the variation of cohesion with void ratio is quite similar in all cases of effective stress state. However, even in effective stress state Masado exhibits considerable amount of cohesion though it mainly contains coarser materials. This may be due to the crushing of individual particles during the shearing process and the assumption made in analyzing the data. That is as- 
suming the linear failure envelops in analyzing the data. Even though negligible, there may be slight contribution in cohesion by small fine fraction of Masado soils under effective stress state. Those reasons may affect the existence of cohesion in Masado soils.

It should be noted here that the analysis conducted according to the hypothesis described in Eq.(9) was not agreed well with the data obtained in direct shear tests conducted at $40 \%$ degree of saturation. It was found that parameter $\chi$ cannot be replaced by degree of saturation as stated in Eq.(9) for the degrees of saturation less than $50 \%$. This is quite similar to that reported by Oberg \& Sallfors ${ }^{20)}$ in presenting their results for non-clayey materials. For favorable results, the parameter $\chi$ should be less than the degree of saturation in determining the actual cohesion of Masado soils when the degree of saturation is less than $50 \%$.

\section{LABORATORY CALIBRATION TEST}

\section{(1) Lightweight dynamic cone penetrometer}

Lightweight dynamic cone penetrometer has been designed and developed in France since 199124),25). The schematic diagram of a LWDCPT is shown in Fig.10. LWDCPT weighs $20 \mathrm{~kg}$, and can be operated by one person at almost any location to a depth of $6 \mathrm{~m}$. It mainly consists of an anvil with a strain gauge bridge, central acquisition unit (CAU), and a dialogue terminal (DT). The hammer is a non-rebound type and weighs $2.0 \mathrm{~kg}$. The stainless steel rods are $14 \mathrm{~mm}$ in diameter and $0.5 \mathrm{~m}$ in length Cones of 2, 4, and $10 \mathrm{~cm}^{2}$ in cross sectional area are available, and a cone holder is used to fix the $2 \mathrm{~cm}^{2}$ cone to the $\operatorname{rod}^{26)}$. The blow from the hammer to the anvil provides energy input, and a unique microprocessor records the speed of the hammer and depth of penetration. The dynamic cone resistance is calculated from a modified form of the Dutch Formula $^{27)}$, as shown in Eq.(10). It should be noted that the expression for energy used in this formula $\left(1 / 2 M V^{2}\right)$ is for kinetic energy, as the energy input is variable and is delivered manually by the blow of the hammer. Dialogue terminal displays not only the real time data but also dynamic cone resistance and penetration depth graphically and in tabular form.

$$
q_{d}=\frac{1}{A} \cdot \frac{1 / 2 M \cdot V^{2}}{1+\frac{P}{M}} \cdot \frac{1}{x_{90^{0}}}
$$

where:

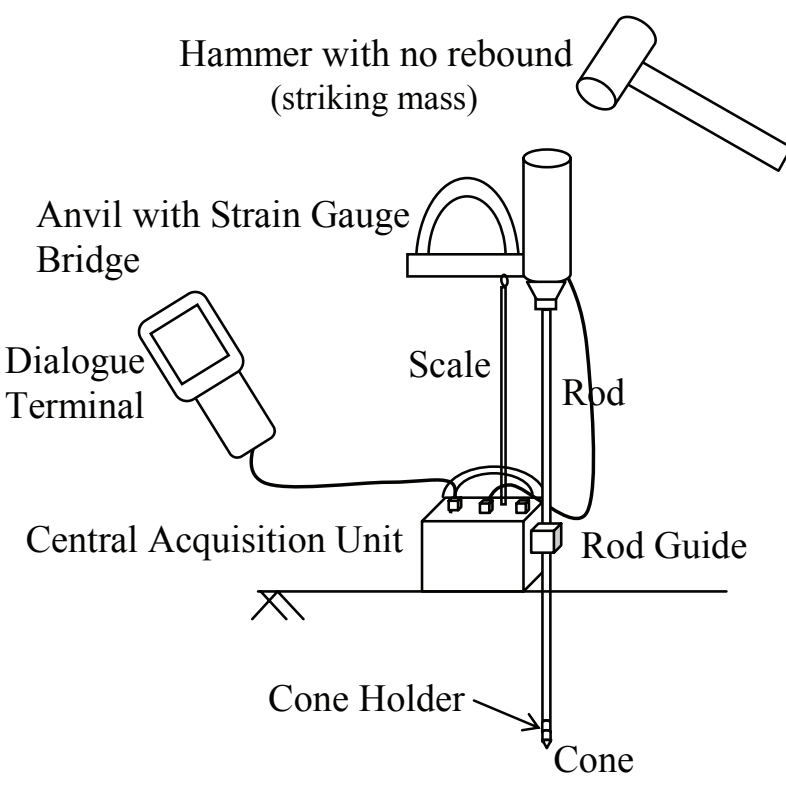

Fig.10 Schematic view of LWDCPT

$x_{90^{\circ}}=$ penetration due to one blow of the hammer ( $90^{\circ}$ cone),

$A=$ area of the cone,

$M \quad=$ weight of the striking mass,

$P$ = weight of the struck mass, and

$V=$ speed of the impact of the hammer.

\section{(2) Calibration tests and interpretation of data}

The main objective of this part of the study was to develop strength correlations between $q_{d}$ and shear strength parameters and there by using the correlations to predict the shear strength parameters from the in-situ LWDCPT tests data. A series of LWDCPT tests was performed under void ratios ranging from 0.6 to 1.1 , and degrees of saturation ranging from $50 \%$ to $90 \%$. A typical calibration test arrangement is shown in Fig.11.

Acryl cylinders each $30 \mathrm{~cm}$ in diameter and $20 \mathrm{~cm}$ in height were fastened through nuts and bolts and porous plate was sealed to the bottom cylinder. The number of acryl cylinders used for each test varies from two to six and some tests were conducted by applying surcharge weights. Prior to each test, water required for a single cylinder was calculated based on the test conditions. Masado soils, which having maximum particle sizes $2 \mathrm{~mm}$, were mixed with the calculated amount of water and immediately fill into four consecutive layers. Light compaction was given to each layer and care was taken to avoid crushing of individual particles. This procedure was repeated to make the chamber in each test. After preparation of required number of cylinders, LWDCPT was mounted on the top cylinder as shown in Fig.11. In the case of tests conducted with surcharge loads LWDCPT was mounted on the surcharge weights. Two to three trials of LWDCPT 


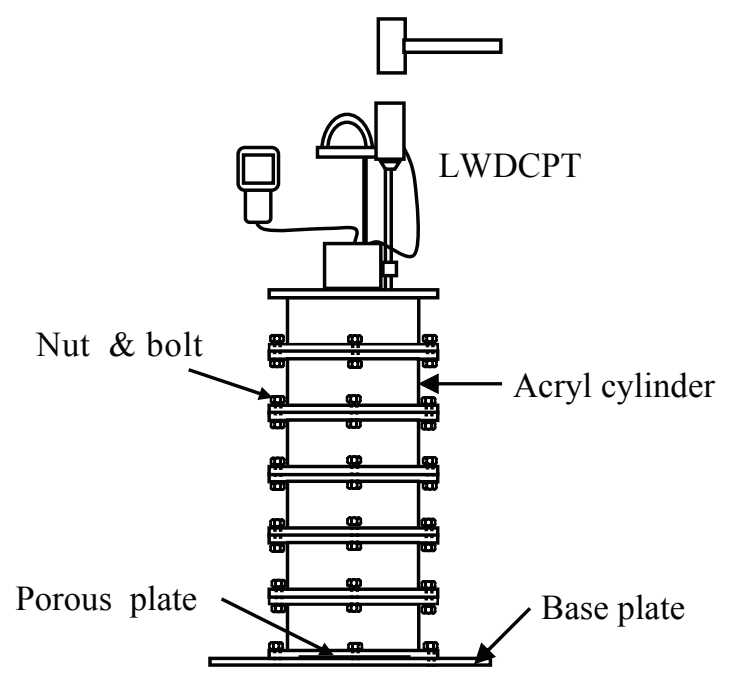

Fig.11 Configuration of the calibration test
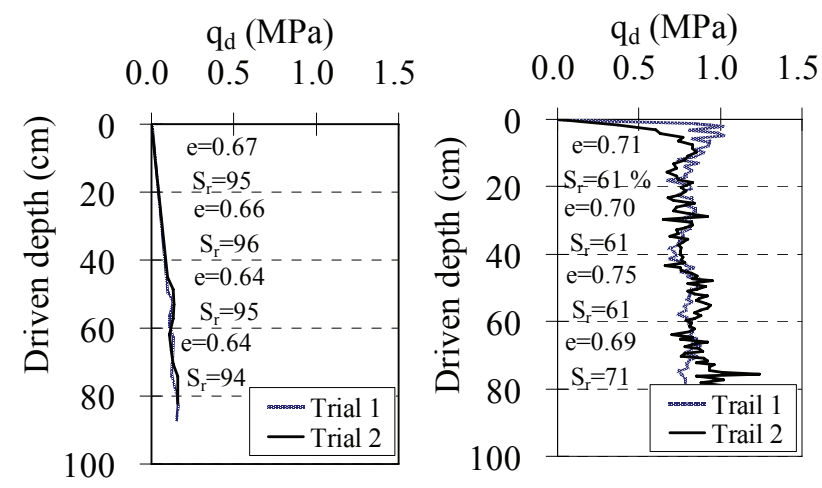

Fig.12 Variation of cone resistance in modeled chamber

tests were performed at each preparation and specimens were taken at each cylinder for water content and void ratio measurements in order to compare the values before and after the tests.

Fig.12 illustrates two soundings recorded at the laboratory calibration tests without applying the surcharge weights. The variations in cone resistance along the soil chamber are given with corresponding void ratios and degrees of saturation measured after the test in each cylinder. The slight variation of degrees of saturation and void ratios were observed along the soil chamber even though those parameters were fixed to a particular value prior to each test. This inequality may be due to the sandy nature of Masado soils and variability in tamping of layers. However, those variations were considered in analyzing the results. Comparatively low values of cone resistance were recorded at high degrees of saturation. Moreover, high void ratios implicate low cone resistance.

All data collected at different void ratios and degrees of saturation were reanalyzed to examine the effect of overburden in determining the cone resistance. Fig.13 illustrates the variation of cone resis-

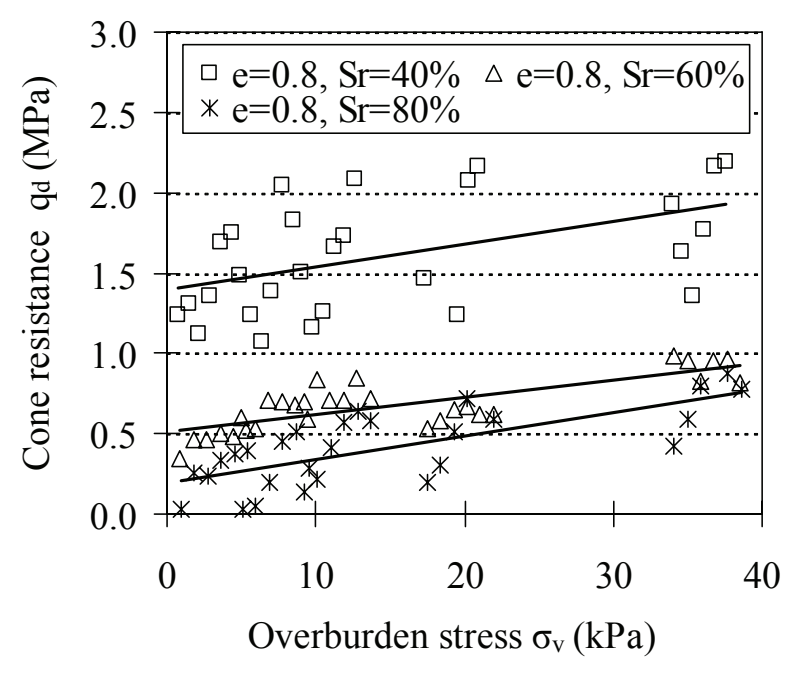

Fig.13 Effect of overburden stress on cone resistance $q_{d}$

tance with overburden stress under different degrees of saturation for void ratio 0.8 . It has been observed that the variation of cone resistance with overburden stress is almost in similar rate irrespective of void ratios and degrees of saturation. The variation of cone resistance shown in Fig.12 was found to be at a constant rate of $0.01 \mathrm{MPa}$ for $1 \mathrm{kPa}$ overburden stress.

\section{(3) Relationship between cone resistance and void ratio at different degrees of saturation}

Fig.13 shows the correlations developed between cone resistance and data pertaining to all range of void ratios and degrees of saturation calculated for 5 $\mathrm{kPa}$ overburden stress. The correction for overburden stress has to be done referring to Eq.(11) and $q_{d 5}$ should be used when calculating void ratios from Fig.14.

$$
q_{d 5}=q_{d}-0.01 \times(\gamma Z-5)
$$

where:

$\gamma=$ the bulk density of soil in $\mathrm{kN} / \mathrm{m}^{3}$, and $Z=$ depth in meters.

The low values of cone resistance at most of the test conditions may be due to disregard of essential gravel fraction in Masado soils in carrying out laboratory penetration tests. However, it is more important to observe the materials have weak shear strength which initiates the slope instability problems. The close investigation of the relationship indicates that cone resistance is drastically decreased at higher void ratios. These are clearly displayed in the curves drawn in Fig.14. The graphical correlations shown in Fig.14 can be approximated to the formula shown in Eq.(12). This facilitates to calculate void ratio from the $q_{d}$ data for known de- 


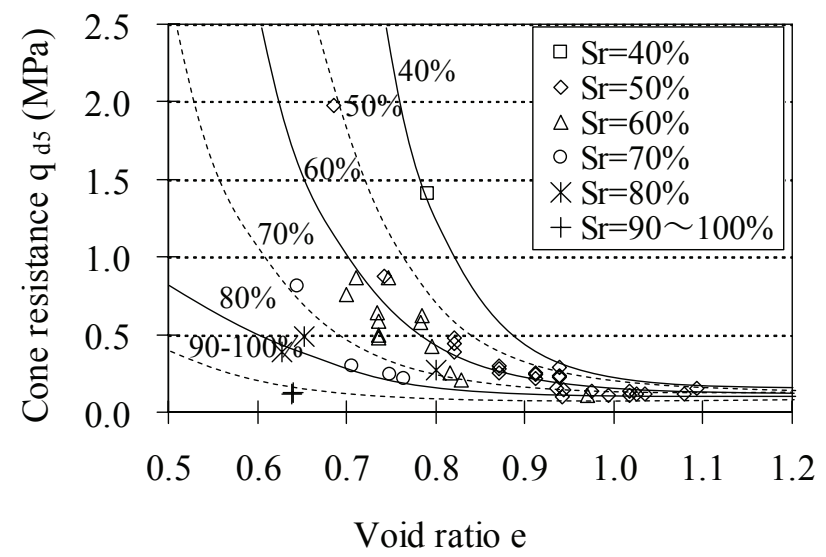

Fig.14 Variation of cone resistance with void ratios under different degrees of saturation

gree of saturation. The proposed empirical relationship can be verified or further modified with the availability of more data especially at degrees of saturation higher than $70 \%$.

$$
e=\left\{[7+0.1(S-50)] \times q_{d 5}\right\}^{\left(\frac{7}{S-100}\right)}
$$

where:

$q_{d 5}=$ Cone resistance calculated from Eq.(11), and $S=$ degree of saturation.

\section{IN-SITU INVESTIGATION}

In order to apply the laboratory findings to the natural slopes, series of in-situ LWDCPT tests were conducted at Ikeno-ue situated on the northern slope of Gagara Mountain in Hiroshima prefecture. Ikeno-ue is a major failure site due to the heavy rainfall on June $29^{\text {th }}, 1999^{1), 3), 28)}$. Detailed site description, in-situ investigation, and their results were presented in the previous literatures published by authors 29,30$), 31), 32$ ). A summary of the results and additional analyses of the data are presented here.

A primary grid as shown in Fig.15 was established having $5 \mathrm{~m}$ intervals spanning $20 \mathrm{~m}$ in width and $50 \mathrm{~m}$ in length. Nodes were numbered from a-1 to e-11. In-situ LWDCPT tests were conducted at each node. Additional in-situ tests were conducted at $2.5 \mathrm{~m}, 1 \mathrm{~m}$, and $0.25 \mathrm{~m}$ grids established within the main grid in order to find the variability of cone resistance spatially.

\section{(1) Classification of soundings (penetrograms)}

Soundings of 55 grid points (a-1 to e-11) were statistically analyzed, and the average cone resistance in $50 \mathrm{~mm}$ intervals was calculated.

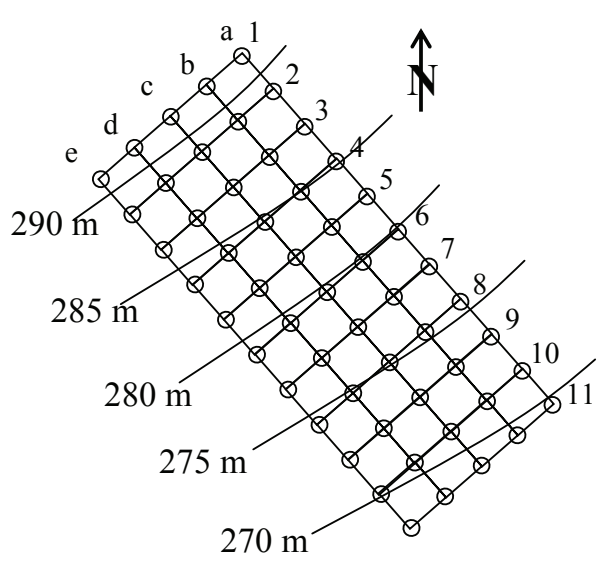

Fig.15 Grid arrangement for preliminary investigation

It was observed that most of the soundings could be fitted into six patterns based on the trend of variation in cone resistance with the depth. Categories were numbered from $\mathrm{A}$ to $\mathrm{F}$ and graphically presented in Fig.16. The detailed characteristics of patterns can be found in the previous literatures ${ }^{31), 32 \text { ) }}$ and an additional description in terms of degree of weathering is presented below.

- Pattern A: This class implicates comparatively thick weathering front over the fresh rock and exhibits fairly uniform weathering profiles.

- Pattern B: Due to the unsmoothness of soundings of this category, it can be expected inconsistent weathering throughout the depth.

- Pattern C: This class also shows unsmoothed soundings due to the differential weathering processes of granites over the years.

- Pattern D: Unlike in patterns B and C, smoothed soundings could be observed specially at shallow depths. Reviewing the topographical conditions at the site, these profiles may be composed of transported materials from the upper areas.

- Pattern E: The trend of increase in cone resistance is similar to that of pattern D. However, the weathering front is thinner in comparison to pattern D.

- Pattern F: This group shows the shallowest profiles and exhibits a very small weathering front. The locations that represent this category consisted of moderately weathered outcrops in the vicinity.

The primary aim of the categorization was to identify the soundings in carrying out in situ tests at Masado slopes and thereby determining the kind of profile at the location. 

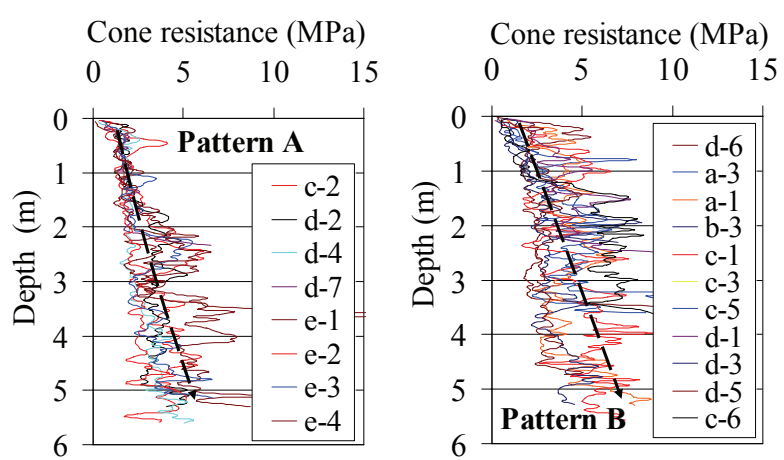

Cone resistance $(\mathrm{MPa})$

$\begin{array}{llll}0 & 5 & 10 & 15\end{array}$

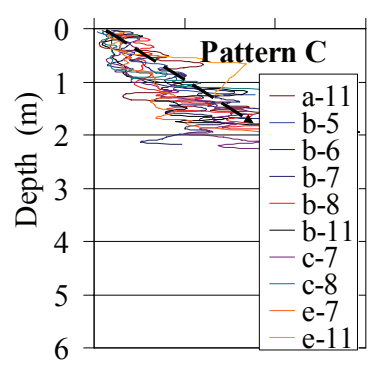

Cone resistance (MPa)

$\begin{array}{llll}0 & 5 & 10 & 15\end{array}$

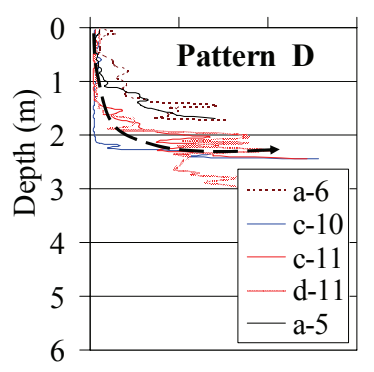

Cone resistanc (MPa)

$\begin{array}{llll}0 & 5 & 10 & 15\end{array}$

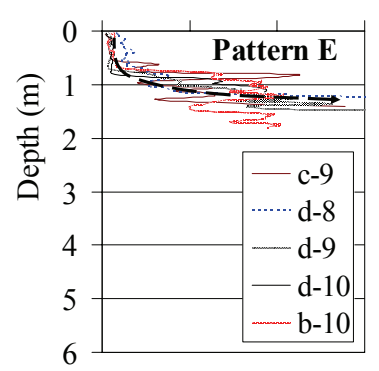

Fig.16 Six patterns of cone resistance varying with depth

\section{Comparison of classification with laboratory calibration results}

The variation of cone resistance in each pattern was compared with Fig.14 in order to determine the void ratio and thereby calculate the shear strength parameters from Figs. 4 and 5. Patterns D $(>2 \mathrm{~m}), \mathrm{E}$ $(>1 \mathrm{~m})$ and a part of pattern $\mathrm{A}(>2 \mathrm{~m})$ which show the cone resistance below $2.5 \mathrm{MPa}$ above the specified depths can be used to determine the shear strength parameters. Those patterns, especially patterns D and E, are of practical importance as the possibility for initiation slope failures at those locations is high due to low values of cone resistance. In other hand patterns $\mathrm{B}, \mathrm{C}$, and $\mathrm{F}$, which show high cone resistance, implicate geotechnical sound materials and possibility of initiation of slope failures is less. The developed relations for determination of shear parameters can be used for the patterns A below $1 \mathrm{~m}$, pattern $\mathrm{B}$ below $0.6 \mathrm{~m}$, and pattern $\mathrm{F}$

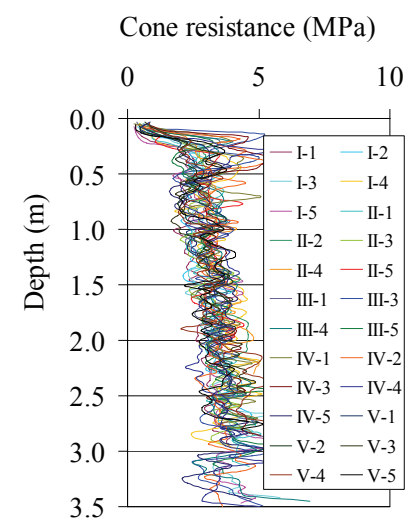

(a)

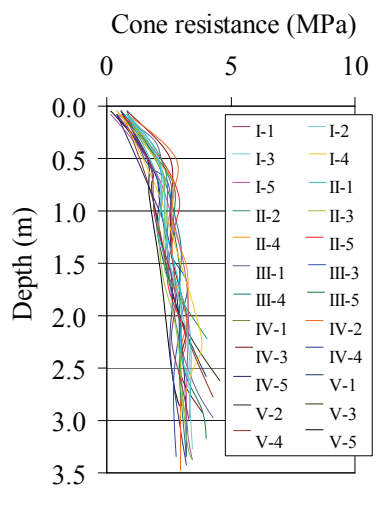

(b)
Fig.17 Soundings of $0.25 \mathrm{~m}$ grid data (a) and their lower limits (b)

below $0.1 \mathrm{~m}$. However, the soundings, which cannot be classified into one of the patterns, have to be treated case-by-case basis in determining the shear strength parameters.

\section{(2) Determination of design $q_{d}$ values}

In general, the occurrence of slope failures under heavy rainfall is due to the saturation of fine particles. Therefore, determination of shear strength of fine particles is must for slope instability analyses. In-situ recorded soundings are due to the different material encountered along profiles. Authors proposed to use the lower boundary of a particular sounding in order to determine the $q_{d}$ values of fine particles. The redrawn penetrograms considering the lower boundary should be used to decide the design $q_{d}$ value for a specific depth of a single profile. Fig.17 (a) illustrates the cone resistance data collected on $0.25 \mathrm{~m}$ grid bounded by d-3, d-4, e-3, and e- 4 of the main grid points. The design penetrograms considering the lower boundary values of each sounding are shown in Fig.17 (b).

\section{(3) Variation of cone resistance before and after rainfall}

Lightweight dynamic cone penetration tests were conducted at selected locations on $12^{\text {th }}$ July 2005 immediately after the rainfall. Rainfall and volumetric water content data collected at the site from $25^{\text {th }}$ June to $15^{\text {th }}$ July, 2005 are shown in Fig.18. The rainfall received from $25^{\text {th }}$ of June to $1^{\text {st }}$ of July is very small and can be assumed a fine climatic condition at the site. Also, it can be observed that the volumetric water content has not been varied significantly during that period at a specific depth. However, the volumetric water content was varied from $18 \%$ to $32 \%$ with the depth varying from 50 $\mathrm{cm}$ to $195 \mathrm{~cm}$ at the site. The average degree of saturation calculated during the fine weather conditions at the site was found to be varied from $40 \%$ 

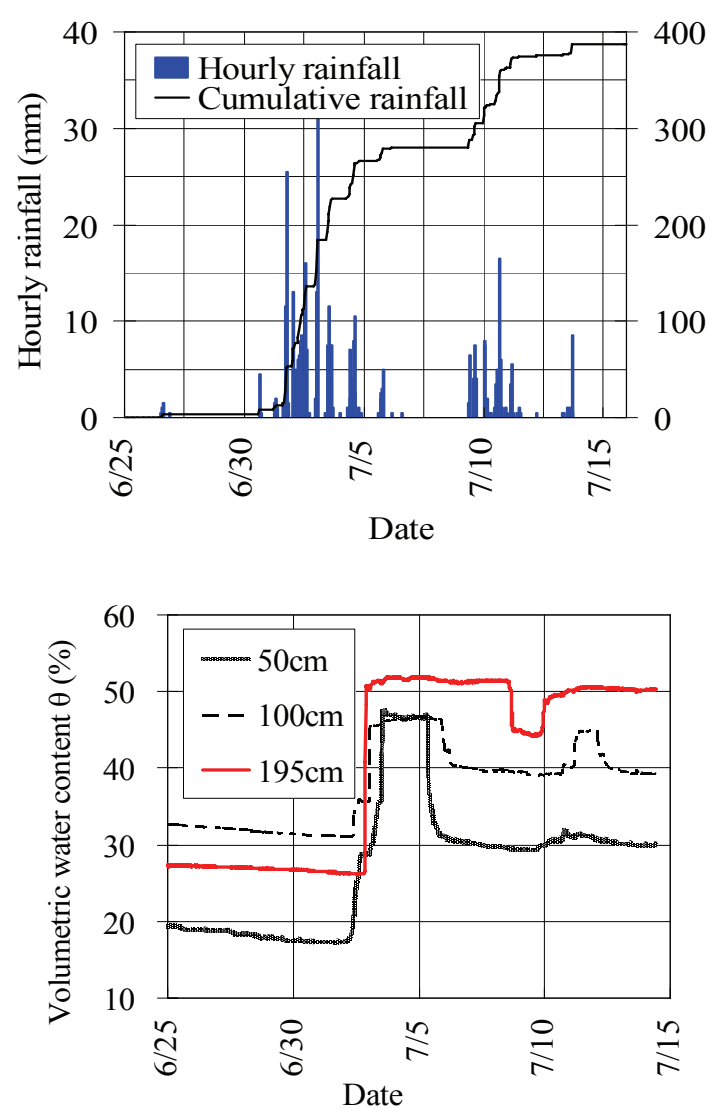

Fig.18 Rainfall and volumetric water content

to $60 \%$ depending on void ratios and the depth. It has been observed that the rainfall received during the first week of month of July was $275 \mathrm{~mm}$ and that from $9^{\text {th }}$ to $12^{\text {th }}$ was $110 \mathrm{~mm}$. The sudden increase of volumetric water content has been observed with the heavy rainfall on $2^{\text {nd }}$ of July. Volumetric water contents during the in-situ tests conducted on $12^{\text {th }}$ July were approximately $30 \%, 45 \%$, and $50 \%$ at 50 $\mathrm{cm}, 100 \mathrm{~cm}$, and $195 \mathrm{~cm}$ depths respectively. Even though in-situ tests were conducted immediately after the rainfall, due to the sandy nature of Masado soils, the seepage may take place faster and the degree of saturation at the time of in-situ tests may not be nearly $100 \%$. Also, the degree of saturation may not be same in all locations and throughout the depth. It depends on the topographical conditions, and the void ratios of subsurface materials. The average degrees of saturation during the in-situ tests were calculated from Eq.(8) and found to be varied from $60 \%$ to $95 \%$.

Data collected from in-situ tests carried out after the rainfall were statistically analyzed and plotted with respect to the location. In order to examine the variation of penetration resistance, in-situ tests carried out before and after the rainfall were plotted in the same penetrograms and shown in Fig.19.

Considerable variations of cone penetration resistance were noted in in-situ tests conducted before different rainfall conditions.

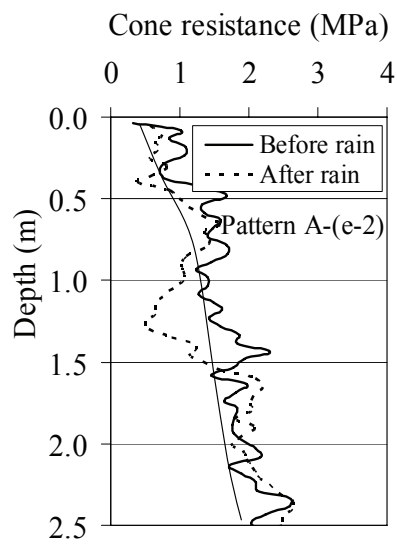

\section{Cone resistance $(\mathrm{MPa})$}

$\begin{array}{llllll}0 & 2 & 4 & 6 & 8 & 10\end{array}$

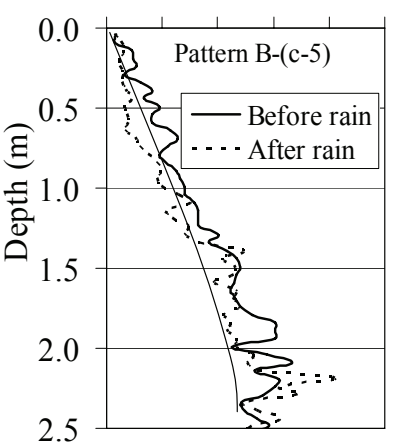

Cone resistance ( $\mathrm{MPa})$

Cone resistance $(\mathrm{MPa})$

$\begin{array}{llllll}0 & 2 & 4 & 6 & 8 & 10\end{array}$

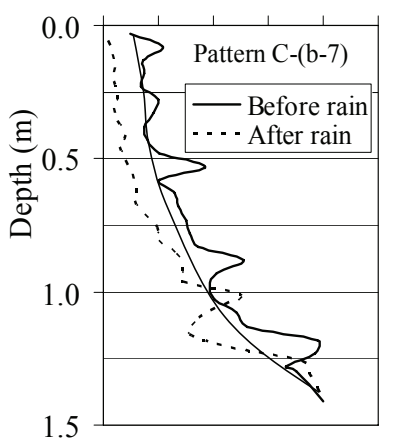

$\begin{array}{lllll}0.0 & 0.5 & 1.0 & 1.5 & 2.0\end{array}$

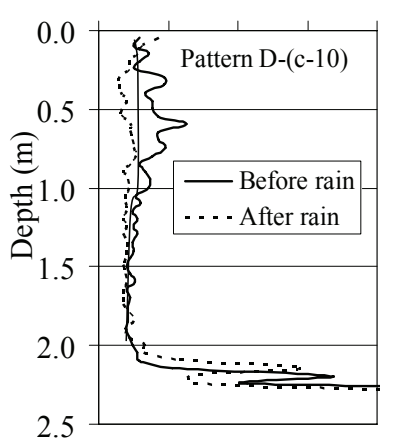

Fig.19 Variation in cone resistance before and after rainfall

and after rainfall. The difference of cone resistance before and after the rainfall is not same along the profiles. That may be due different materials encountered along the soil strata. However, it is quite clear that there may be clear reduction of penetration resistance due to partial saturation of underneath materials. As suggested the design penetrograms were drawn considering the lower boundary for the soundings recorded before the rainfall as shown in Fig.19. This has to be used for calculation of shear parameters. However, more data is required to draw reliable outputs and to make solid relationships for the reduction of cone resistance under

\section{(4) Calculation of void ratios and shear pa- rameters from the data of $q_{d}$}

Referring to the Fig.14 and Eq.12, void ratios were calculated using the data of $q_{d}$ for locations illustrated in Fig.20. Apparent cohesion was calculated thereafter referring to the Fig.5. In predicting void ratios, the average degree of saturation in a fine day was assumed to $40 \%$. The assumed values of degree of saturation are well within those calculated from volumetric water content variations shown in Fig.18. Fig.20 illustrates the variation of 

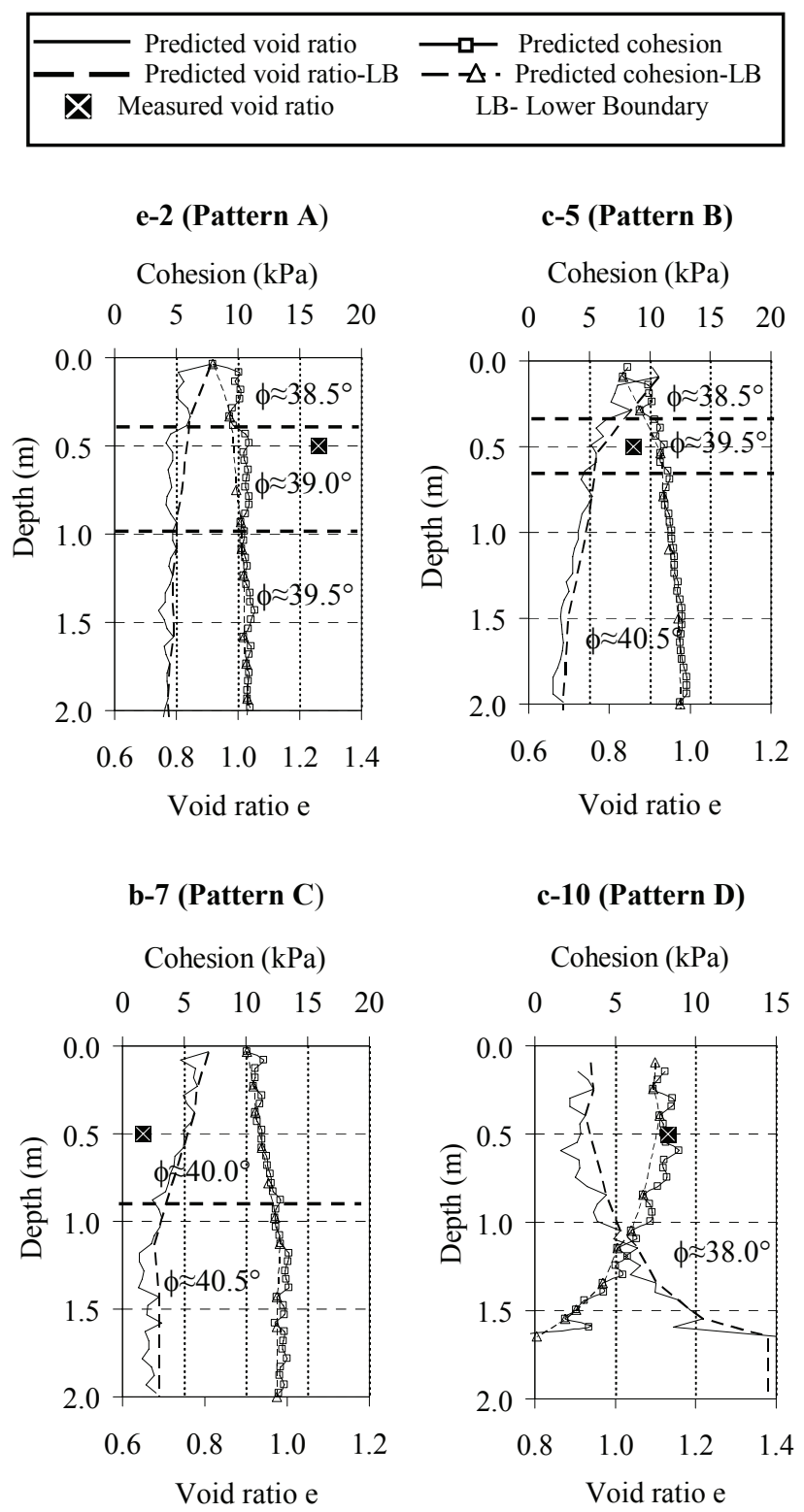

Fig.20 Variation of void ratio and cohesion along profiles

predicted void ratios and predicted cohesion at four grid points. Predicted void ratios, cohesion and angle of internal friction from the lower boundary of $q_{d}$ values are also shown in Fig.20.

As calculation of shear parameters thoroughly depend on the void ratios predicted from cone resistance data from Fig.14, the reliability of outcomes more or less depend on the accuracy of predicting the void ratios from the cone resistance data. The predicted void ratios from Eq.(12) were compared with the in situ samples taken at the depth of $0.5 \mathrm{~m}$. The measured values $\left.{ }^{33)}, 34\right)$ of void ratios are plotted in the Fig.20. None of the locations showed good agreement with measured and calculated void ratios. It was observed that predicted void ratios are rather close to measured values in locations c-5 (pattern B) and b-7 (pattern C) among the four locations investigated. Void ratios calculated and measured in locations e-2 (pattern A), and c-10 (pattern B) showed considerable difference in values than those observed in c-5 and b-7. Reasons for these differences are explained below.

It should be noted here that, the prediction of void ratios was performed using reconstituted Masado soils having particle size less than $2 \mathrm{~mm}$ at the laboratory. Also, the exact degree of saturation was not known at the time of conducting in-situ tests and carrying out sampling at the site. This has an effect on the prediction of void ratios from Fig.14 and there is a possibility of deviating predicted void ratios shown in Fig.20. Even though in-situ samples were taken with care, there may be possibility of sampling errors accounted for the differences of measures and predicted void ratios.

Patterns A, B, and $\mathrm{C}$ which show fairly unsmoothed soundings due to contact of cone with un-weathered particles such as gravels or cobbles, may show considerable variation of properties even at same depth level. In addition, the proposed curves in Fig.14 for void ratios vary with cone resistance especially above the $1 \mathrm{MPa}$ was based on a very few data and possibility of errors in predicting the void ratios may be significant. These may affect the difference of measured and predicted void ratios. The difference of measured and predicted values of void ratio of c-10 (pattern D) may be due to the less sensitivity of low $q_{d}$ values in predicting void ratios from Fig.14. More test data and analyses are needed to clearly define the values of void ratios for low cone resistance data.

As a whole, authors attempted to introduce an efficient methodology for determination of shear strength parameters by establishing several correlations between laboratory and field data collected from lightweight dynamic cone penetrometer. More in-situ samples of soils should be taken to determine the void ratio and must be compared with the predicted values at known degrees of saturation before this method is reliably applied for determination of shear strength parameters.

\section{CONCLUDING REMARKS}

The primary objective of this paper was to present an efficient and simple methodology to find the shear strength parameters of Masado soils based on the lightweight dynamic cone penetration test data. On the basis of the content of this paper following conclusions can be drawn.

1. The angle of internal friction of reconstituted Masado soils was found to be linearly varying with void ratios approximately. Fairly good linearly varying relations were established be- 
tween void ratios and apparent cohesion under different degrees of saturation.

2. It was found that the pore water pressure effect is quite significant in determining the cohesion of Masado soils. The reduction of apparent cohesion due to suction $\left(-u_{w}\right.$ as $\left.u_{a}=0\right)$ was found to be $10 \%$ to $60 \%$ depending on the degree of saturation.

3. Laboratory calibration tests revealed that there is fairly good relations between $\mathrm{q}_{d}$ with void ratios of reconstituted Masado under different degrees of saturation. Empirical equation was developed to calculate the void ratio from cone resistance data at a known degree of saturation.

4. A method of determining shear strength parameters from the data of $q_{d}$ was proposed based on the correlations developed between void ratios with $q_{d}$ and shear parameters.

5. Reduction in cone resistance was observed in in-situ tests carried out after the rainfall. The variation of penetration resistance more or less depends on the different material encountered along the profile.

6. A method of determining design shear strength parameters for analysis of slopes was proposed based on the lower boundary of cone resistance data.

7. The deviation of predicted and measured void ratios may be mainly due to the difference between the reconstituted and natural state of soils. More data is required before the established method can be reliably used.

The simple approach presented here in determining the shear strength parameters will be useful for the geotechnical engineers and researchers involved in slope investigation activities. More investigations and studies must be undertaken to further develop the proposed method to firmly establish correlations between cone resistances and shear strength parameters under different conditions.

ACKNOWLEDGMENTS: The authors gratefully acknowledge the valuable suggestions and comments by Dr. Koji Ichii, Associate professor, Graduate School of Engineering, Hiroshima University and the financial assistance provided by the Ministry of Science and Education, Japan.

\section{REFERENCES}

1) Dissanayake, A. K. : A Study on the initiation of rain induced landslides in decomposed granite slopes, PhD Thesis, Dept. of Social and Env. Engng., Faculty of Engineering, Hiroshima University, Japan, pp. 8-49, 2002.
2) Athapaththu, A. M. R. G., Tsuchida, T., Sato, T., and Suga, K. : Evaluation of in-situ shear strength of natural Masado slopes, Geotechnical Division, Int. Offshore and Polar Engng. 2006, San Francisco, Vol. 2, pp. 324-331, 2006.

3) Thi ha: Study on the mechanism of slope instability induced by rainfall in decomposed granite slope, PhD Thesis, Hiroshima University, Japan, 2005 (in Japanese).

4) www.mlit.go.jp/river/sabo/link20.htm.

5) Anderson, S. A., and Sitar, N. : Analysis of rainfall induced debris flows, J. Geotech. Engng., Vol. 121, No. 7, pp. 544-552, 1995.

6) Brand, E. W. : Some thoughts on rain induced slope failures, Proc. $10^{\text {th }}$ Int. Conf. Soil Mech. \& Found. Engng., Stockholm, Vol. 3, pp. 373-376, 1981.

7) Sangrey, D. A., and Williams K. O. H. : Prediction ground water response to precipitation, J. Geotech. Engng., Vol. 110, No. 7, pp. 957-975, 1984.

8) Galer, M. M. : A Study on the mechanical properties of undisturbed decomposed granite based on testing and triaxial testing results under elevated confining pressure, $P h D$ Thesis, Hiroshima University, Japan, pp. 1-34, 1999.

9) Jiban chosahou, The Japanese geotechnical society, Ed. 1, pp. 208-209, 1995 (in Japanese).

10) Terzaghi, K. : The shear resistance of saturated soils, Proc. of $1^{\text {st }}$ Int. Conf. on Soil Mech. \& Found. Engng., Vol. 1, pp.54-56, 1936.

11) Bishop, A. W. : The principle of effective stress, Norwegian Geotech. Inst., Publication 32, Oslo, pp. 1-4, 1959.

12) Bishop, A. W., Alpan, I., Blight, G. E., and Donald, I. B. : Factors controlling the strength of partly saturated cohesive soils, Proc. of the ASCE Research Conf. on Shear Strength of Cohesive Soils, Boulder, Colorado, pp. 505-532, 1960.

13) Donald, I. B. : The mechanical properties of saturated and partly saturated soils with special reference to negative pore water pressure, PhD Thesis, University of London, London, 1961.

14) Blight, G. E. : Strength and consolidation characteristics of compacted soils, PhD Thesis, University of London, London, 1961.

15) Vanapalli, S. K., and Fredlund, D. G. : Comparison of different procedures to predict unsaturated soil shear strength, Advances in unsaturated geotechnics, Geotech. Special Pub., Colorado, No. 99, pp. 195-209, 2000.

16) Fredlund, D. G., and Morgenstern, N. R. : Stress state variables for unsaturated soils, ASCE J. Geotech. Engng. Div., Vol. 103, GT. 5, pp. 447-466, 1977.

17) Fredlund, D. G., Morgenstern, N. R., and Widger, R. A. : The shear strength of unsaturated soils, Can. Geotech. J., Vol. 15, No. 3, pp. 313-321, 1978.

18) Fredlund, D. G., and Rahardjo, H. : Soil mechanics for unsaturated soils, John Wiley \& Sons. Inc., New York, pp. 217-259, 1993

19) Vanapalli, S. K., Freduland, D. G., Pufahl, D. E., and Clifton, A. W. : Model for the prediction of shear strength with respect to soil suction, Can. Geoetch. J., Vol. 33, pp. 379-392, 1996.

20) Oberg, A. L., and Sallfors, G. : Determination of shear strength parameters of unsaturated silts and sands based on the water retention curve, Geotech. Test. J., ASTM, Vol. 20, No. 1, pp 40-48, 1997.

21) Geotechnical test, basic and notes, Direct shear test, JG 0560, JG 0561, Jap. Geotech. Soc., pp. 121-134, 2001 (in Japanese).

22) Nakayama,Y., Nishida, K., Aoyama, K., and Sawa,K. : Sampling and testing method of undisturbed Masado, Proc. of Symp. on Weathered Residual Soil, Jap. Geotech. Soc., pp.117-120, 1988 (in Japanese). 
23) Yagi, N., Enoki, A., and Yatabe, R. : Shear characteristic of undisturbed Masado, Proc. of Symp. on Weathered Residual Soil, Jap. Geotech. Soc., pp.155-160, 1988 (in Japanese).

24) Langton, D. D. : The PANDA-Lightweight Penetrometer for soil investigation and monitoring material compaction, Ground Engineering, September 1999, pp. 33-37, 1999.

25) Ito, Y.,Iwasaki, T., Nobumoto, M., Miyata, Y., and Murata, Y.: The application case of a new portable dynamic probing test, Symp. on Application of Recent Geotech. Investigations and Testing Methods, pp. 23-26, 2006 (in Japanese).

26) www.sol-solution.com, Panda 2 Hand book, Ver. 1.03, France

27) Cassan, M. : Les essays in situ en mechanique des sols, realization et interpretation, Eyrolles, Paris, $2^{\text {nd }}$ ed., Vol. 1, pp. 146-151, 1988.

28) Thi ha, Moriwaki, T., Dissanayake, A. K., Uy, D. A., and Yamamoto, M. : Study on the mechanism of slope failures induced by rainfall, 1st Int. Conf. on Civil and Env. Engng., Hiroshima University, pp. 99-108, 2002.

29) Athapaththu, A. M. R. G., Tsuchida, T., Suga, K., and Sato, T. : Investigation of spatial variability of natural Masado slopes, 5th Int. Conf. on Civil and Env. Engng., Hiroshima University, pp. 67-78, 2006.
30) Athapaththu, A. M. R. G., Tsuchida, T., Suga, K., and Kano, S. : Geo-statistical analysis of the spatial variability of Masado formations, Symp. of the Jap. Geotech. Soc., Kagoshima, No139, pp. 107-112, 2006.

31) Athapaththu, A. M. R. G., Tsuchida, T., Sato, T., and Suga, K. : A lightweight dynamic cone penetrometer for the investigation of natural Masado slopes, $4^{\text {th }}$ Int. Conf. on Civil and Env. Engng., Hiroshima University, pp. 279-284, 2005.

32) Athapaththu, A. M. R. G., Tsuchida, T., and Suga, K., and Nakai, S. : Evaluation of in-situ strength variability of Masado slopes, Jap. Soc. Civil. Engng, (Unpublished).

33) Takashi, S. : Research about evaluating strength of natural Masado slopes during rainfall, Master Thesis, Dept. of Social and Environmental Engineering, Faculty of Engineering, Hiroshima University, Japan, pp. 60, 2006 (in Japanese).

34) Suga, K. : Strength evaluation of natural Masado slopes with lightweight dynamic cone penetrometer, Master Thesis, Dept. of Social and Environmental Engineering, Faculty of Engineering, Hiroshima University, Japan, pp. 101-102, 2007 (in Japanese).

(Received January 18, 2007) 